\title{
Mycobacterium leprae: ASPECTOS DA RESISTÊNCIA AOS FÁRMACOS NA POLIQUIMIOTERAPIA
}

\author{
Valter Batista Duo Filho \\ Naiara Cristina Ule Belotti ${ }^{1}$ \\ Vânia Del Arco Paschoal ${ }^{2}$ \\ Susilene Maria Tonelli Nardi ${ }^{1}$ \\ Heloisa da Silveira Paro Pedro ${ }^{1}$
}

DUO FILHO, V. B.; BELOTTI, N. C. U.; PASCHOAL, V. D. A.; NARDI, S. M. T.; PEDRO, H. da S. P. Mycobacterium leprae: aspectos da resistência aos fármacos na poliquimioterapia. Arquivos de Ciências da Saúde da UNIPAR, Umuarama, v. 25, n. 1, p. 79-85, jan./ abr. 2021

\begin{abstract}
RESUMO: Introdução: O diagnóstico da hanseníase possui números significativos que causam preocupação à saúde pública. Os casos de resistência medicamentosa nessa doença se iniciaram em meados dos anos 60 e diante do problema, a Organização Mundial da Saúde instituiu em 1981 a poliquimioterapia, associação dos antibióticos rifampicina, dapsona e clofazimina, tratamento atual de escolha. A resistência aos fármacos na hanseníase é reportada pela literatura, desvelando um obstáculo à sua eliminação. Apresentamos nessa revisão os principais aspectos da resistência medicamentosa no tratamento para hanseníase e seus impactos. Metodologia: Revisão sistemática sobre os aspectos da resistência medicamentosa utilizando a pesquisa exploratória como metodologia de abordagem. Foram pesquisados os termos resistência medicamentosa, hanseníase, recidiva, alterações genéticas e os operadores booleanos "and" e "or" na busca. Resultados e discussão: A dificuldade de tomar a medicação corretamente foi um dos principais fatores que acarretaram resistência do bacilo Mycobacterium leprae aos fármacos. Homens de países norte e sul-americanos e asiáticos foram os mais atingidos por episódios de resistência. A resistência medicamentosa é uma das principais causas de recidivas em hanseníase. O principal fármaco causador de resistência medicamentosa descrito nos trabalhos foi a dapsona $(46,6 \%)$ e a maioria das alterações genéticas encontradas estão no gene rpoB; $23,2 \%$ dos registros relatados foram de resistência secundária aos fármacos e, também, sete casos de resistência múltipla a esses medicamentos. Conclusão: Os principais aspectos da resistência medicamentosa na hanseníase são os equívocos ao ingerir os medicamentos e as alterações genéticas na bactéria. Os impactos causados estão na dificuldade de refazer o tratamento, a possibilidade de nova transmissão e o aparecimento de sintomas mais graves.
\end{abstract}

PALAVRAS-CHAVE: Hanseníase; Poliquimioterapia; Fármacorresistência Bacteriana; Impactos na Saúde.

\section{DRUG RESISTANCE IN MULTIDRUG THERAPY FOR Mycobacterium leprae}

ABSTRACT: Introduction: The diagnosis of leprosy has significant numbers causing public health concern. Reports of drug resistance in this disease begun in the mid-1960s and due to this problem, the World Health Organization instituted a multidrug therapy with rifampicin, dapsone, and clofazimine antibiotic association in 1981, which is currently the first-choice treatment for leprosy. Cases of drug resistance have been reported in literature, revealing an obstacle to the eradication of the disease. This paper has the purpose of presenting the key aspects and impacts of drug resistance in the treatment for leprosy. Methods: Systematic review of the drug resistance aspects using exploratory research as an approach methodology. The authors searched the terms drug resistance, leprosy, recurrence, genetic alterations, and the Boolean operators "and" and "or" between them. Results and discussion: The difficulty in taking the medication correctly was one of the key factors that led to drug resistance for Mycobacterium leprae. Men from North and South American, as well as from Asian countries, were the most affected by episodes of resistance. Drug resistance is one of the main causes of leprosy recurrences. Dapsone was the most frequently identified drug resistance in the studies $(46.6 \%)$, while most of the genetic alterations were found in the $r p o B$ gene; $23.2 \%$ of the cases were from secondary resistance episodes, and seven cases of multiple resistance were reported. Conclusion: The misconceptions when taking the treatment and the Mycobacterium leprae genetic alterations have been described as the key aspects of drugs resistance in leprosy and the impacts caused are the difficulty in redoing the treatment, the possibility of new transmission, and the appearance of more severe symptoms.

KEYWORDS: Leprosy; Drug Therapy, Combination; Drug Resistance Bacterial; Impacts on Health.

\section{Introdução}

A hanseníase é uma doença crônica e infectocontagiosa, de alto poder incapacitante causada pelo Mycobacterium leprae, um bacilo álcool-ácido resistente (BAAR) também conhecido por bacilo de Hansen (BOECHAT; PINHEIRO, 2012).

$\mathrm{O}$ primeiro fármaco utilizado no tratamento da hanseníase, a sulfona, conhecida por dapsona e ainda utilizada, foi disponibilizado no final da década de 40 apresentando bons resultados (BOECHAT; PINHEIRO, 2012; NOORDEEN, 2016), porém em meados dos anos 50 e 60 foram descritos os primeiros casos de resistência ao fármaco. A monoterapia foi entendida como a principal causa de resistência à dapsona ou rifampicina (CAMBAU et al., 2018).

Diante do problema da resistência aos fármacos, em 1981, a Organização Mundial da Saúde (OMS) definiu que todos os casos de hanseníase deveriam ser tratados com a combinação de dapsona e rifampicina e implantou o uso de clofazimina para casos multibacilares, intitulando a poliquimioterapia (PQT), que continua sendo o tratamento mais indicado e eficaz no combate contra a doença (SMITH et al., 2017; CAMBAU et al., 2018).

Mesmo com todos os esforços da OMS e a implantação da PQT, os casos de resistência medicamentosa,

DOI: 10.25110 /arqsaude.v25i1.2021.7911

${ }^{1}$ Núcleo de Ciências Biomédicas - Laboratório de Micobactérias do Instituto Adolfo Lutz (IAL) de São José do Rio Preto - SP.

E-mail: heloisa.pedro@ial.sp.gov.br

${ }^{2}$ Faculdade de Medicina de São José do Rio Preto - SP (FAMERP) - Rua Av. Brigadeiro Faria Lima, 5416 - Vila São Pedro, São José do Rio Preto - SP. 
até mesmo múltipla, ainda existem e são um obstáculo diante da estratégia de eliminação da doença (ORGANIZAÇÃO MUNDIAL DA SAÚDE, 2016). Os fundamentos da resistência aos fármacos podem ser variados, desde causas genéticas (LIU et al., 2015) até pacientes que não fazem o tratamento de forma correta, desencadeando esse problema (BONA et al., 2015). Além dos impactos no tratamento, a resistência medicamentosa na hanseníase se firma como uma das principais causas de recidiva, o que pode gerar conflitos no futuro prognóstico e novo tratamento dos pacientes, uma vez que a PQT poderá não ser mais eficaz no controle do bacilo (DIÓRIO et al., 2009).

Os métodos que identificam a resistência medicamentosa são baseados em técnicas moleculares de detecção à susceptibilidade aos fármacos do M. leprae, buscando mutações e outras informações que possam dar maiores detalhes sobre os mecanismos dessa bactéria, ajudando nesse aspecto e contribuindo na eliminação da doença (ARAUJO et al., 2017; LAVANIA et al., 2018).

Perante os atuais dados epidemiológicos da hanseníase e o aumento de casos de resistência aos fármacos de primeira linha, mais estudos são necessários, na tentativa de contribuir de maneira eficaz aos programas de controle e estratégias de eliminação da doença no mundo (BRASIL, 2010; ORGANIZAÇÃO MUNDIAL DA SAÚDE, 2016).

Este estudo teve como objetivo apresentar os principais aspectos da resistência do Mycobacterium leprae aos fármacos no tratamento.

\section{Poliquimioterapia}

A poliquimioterapia (PQT) é o esquema terapêutico específico para hanseníase, recomendado pela OMS e preconizado pelo Ministério da Saúde do Brasil (MS). Conduzida por esquema padronizado do tratamento levando em consideração a classificação operacional do paciente: paucibacilar ou multibacilar (CRESPO; GONÇALVES, 2014; BRASIL, 2014).

A classificação operacional é de extrema importância para o correto esquema de tratamento, além da consideração de outros critérios como idade, peso e pessoas intolerantes a um dos fármacos do esquema padrão. Considera-se curado o paciente que fez a administração do número de doses preconizadas pelo esquema terapêutico, dentro do prazo recomendado. Trata-se de um tratamento ambulatorial que está disponível em unidades públicas de saúde. A PQT elimina bacilos viáveis e impede sua multiplicação, proporcionando à cura. $\mathrm{O}$ tratamento é o único meio capaz de interromper o ciclo da doença, pois quando realizado de maneira correta, cessa a cadeia de transmissão (BOECHAT; PINHEIRO, 2012).

\section{Esquemas de tratamento}

Os esquemas terapêuticos devem ser utilizados de acordo com a classificação operacional do paciente, podendo ser paucibacilar ou multibacilar e infantil ou adulto. Em casos paucibacilares, a duração do tratamento é de seis cartelas completas. Cada cartela contempla uma dose supervisionada com duas capsulas de rifampicina $(300 \mathrm{mg})$ e uma de dapsona (100mg), além de 28 doses diárias autoadministradas de dapsona (100mg). Para crianças, os mesmos medicamentos são utilizados, porém com dosagem reduzida. $\mathrm{O}$ tratamento só estará concluído com seis doses supervisionadas e no máximo em até nove meses. Na sexta dose, os pacientes deverão ser submetidos a exames físicos, dermatológicos e neurológicos para receber alta por cura (BRASIL, 2014).

Para casos multibacilares a duração do tratamento é de 12 cartelas completas. Em cada uma das cartelas, há a dose supervisionada mensal com $600 \mathrm{mg}$ de rifampicina (02 cápsulas de $300 \mathrm{mg}$ ), $100 \mathrm{mg}$ de dapsona e 300mg de clofazimina (em 03 capsulas de 100mg) e nas doses autoadministradas são tomadas diariamente $50 \mathrm{mg}$ de clofazimina e $100 \mathrm{mg}$ de dapsona e, a terapêutica só estará concluída na décima segunda dose supervisionada ou no máximo em 18 meses. Para crianças a dosagem é reduzida. Ao final do tratamento os pacientes também deverão ser submetidos a exames para receber alta por cura. Os doentes multibacilares que incomumente não apresentarem melhora do quadro clínico, com presença de lesões ativas no final do tratamento preconizado de 12 doses/cartelas, deverão ser encaminhados para avaliação no serviço de referência (BRASIL, 2014).

\section{Diagnóstico para resistência aos fármacos na hanseníase}

\section{Metodologia de Shepard}

Ao longo do processo da evolução, o M. leprae teve seu genoma reduzido, apresentando no período atual, um conjunto mínimo de genes que como consequência, eliminou várias vias metabólicas deixando o bacilo com requisitos de multiplicação muito específicos (MARRI; BANNANTINE; GOLDING, 2006; AKINOLA; MAZANDU; MULDER, 2016; CHAVARRO-PORTILLO et al., 2019), fato que pode explicar sua impossibilidade de multiplicação em meios artificiais.

Por ser um microrganismo não cultivável por técnicas tradicionais, o $M$. leprae exige técnicas capazes de permitir a sua multiplicação in vivo. Uma delas é denominada método de Shepard. O método permitiu que fosse identificada a resistência à dapsona por meio da inoculação de bacilos nas patas de camundongos. Para a operação do método há a necessidade de grande quantidade de bacilos, que são inoculados no coxim plantar desses animais. $\mathrm{O}$ crescimento do bacilo é analisado durante a vigésima quinta até a trigésima semana após a inoculação, onde deverão ser encontrados de $10^{5}$ a $10^{6}$ bacilos (MATSUOKA, 2010). Deve existir um grupo-controle e outros grupos de camundongos que receberão o tratamento com os diferentes fármacos testados, que são administrados por via enteral. Ao observar a multiplicação do bacilo no grupo-controle, a contagem dos bacilos entre os diferentes grupos experimentais é realizada. A confirmação da resistência medicamentosa se dá se um isolado for capaz de se proliferar na pata do camundongo tratado com o fármaco. $\mathrm{O}$ método constitui padrão-ouro na constatação da resistência aos fármacos, no entanto, não é uma técnica de diagnóstico prático para muitas amostras (LUZHNOVA et al., 2016). 
Técnica de reação em cadeia da polimerase e DNA-strip

Com o avanço da biologia molecular e dos problemas éticos, no quesito de testes com animais, novos métodos diagnósticos para a pesquisa da resistência medicamentosa na hanseníase foram desenvolvidos. O Geno Type Leprae $D R^{\circledR}$ trata-se de um sistema diagnóstico que é capaz de detectar a presença do $M$. leprae na amostra e suas resistências primária e secundária aos fármacos ao mesmo tempo (CAMBAU et al., 2012).

O DNA é extraído de amostras com baciloscopia positiva e amplificado por reação em cadeia da polimerase (PCR). Após esse processo, através de fitas Hain $^{\circledR}$, que possuem revestimento com oligonucleotídeos específicos (membrana strip) é possível visualizar a detecção da bactéria e de sua resistência ou não, através de hibridização reversa e reação de coloração enzimática (CAMBAU et al., 2012).

\section{Resistência aos fármacos}

Principais aspectos da resistência medicamentosa na hanseníase

A manifestação da resistência medicamentosa é uma ameaça para a intervenção em doenças infectocontagiosas. Com o desenvolvimento e a aplicação da PQT, a batalha na busca da cura e interrupção da transmissão da hanseníase é bem-sucedida (BOECHAT; PINHEIRO, 2012), porém os registros de casos da doença no mundo ainda são altos. Em razão do surgimento de cepas bacterianas resistentes e da rifampicina ser o principal fármaco no esquema de PQT, é importante monitorar esse aparecimento.

Os primeiros casos de resistência aos fármacos na hanseníase foram notificados na década de 60, com o registro de pacientes que não se curavam com uso de dapsona, incluindo assim, no tratamento, a rifampicina, que também não demorou a notificar casos de resistência que até hoje são atuais em regiões endêmicas (CAMBAU et al., 2018).

Em casos de resistência à rifampicina, as fluoroquinolonas tornam-se os fármacos indicados para o tratamento (MARQUES et al., 2012, CAMBAU et al., 2018), mas já foram relatadas cepas de $M$. leprae resistentes a essa linha de fármacos. A resistência à clofazimina ainda é incomum (MACHADO et al., 2018).

Os casos de resistência medicamentosa também aumentam os registros de recidivas na hanseníase; é considerado como recidiva todo caso que, após concluir com êxito o tratamento preconizado, apresente novos sinais e sintomas (DIÓRIO et al., 2009).

Para lutar contra o avanço no registro de casos de hanseníase e o aparecimento de cepas resistentes aos fármacos, é imprescindível manter a atenção nas informações e dados da susceptibilidade aos fármacos globalmente (ORGANIZAÇÃO MUNDIAL DA SAÚDE, 2016), bem como acompanhar e controlar os casos de resistência primária (registro de resistência medicamentosa em casos novos de hanseníase) e secundária (registro de resistência aos fármacos em um segundo tratamento, geralmente em recidivas) (ALVES; FERREIRA; FERREIRA, 2014).
Aspectos moleculares da resistência medicamentosa na hanseníase

A resistência aos fármacos no $M$. leprae ocorre em consequência de alterações genéticas nos alvos desses fármacos e da redução da permeabilidade da parede celular (RATLEDGE; DALE, 2009).

A permeabilidade da membrana da célula é imprescindível para que o fármaco tenha o efeito desejado. As membranas são constituídas por lipídios e fosfolipídios que concedem uma penetração mais retardada e eficaz do medicamento através das porinas. Nesse tipo de mecanismo, as alterações estruturais, de tamanho, número ou seletividade das porinas, a nível de membrana, são responsáveis pela modificação da permeabilidade dos antibióticos. As fluoroquinolonas, fármacos de segunda linha penetram no gênero Mycobacterium através das porinas e, qualquer alteração na sua função ou quantidade acarretará a resistência (RATLEDGE; DALE, 2009).

Quando se falam em alterações genéticas, três principais genes da bactéria estão envolvidos: $r p o B$, relacionado com a resistência à rifampicina; folP1, relacionado à resistência à dapsona e $g y r A$, relacionado à resistência aos fármacos de segunda linha (fluoroquinolonas) (BONA et al., 2015; CAMBAU et al., 2018).

Em relação ao mecanismo de ação da rifampicina, o fármaco adere à RNA polimerase das micobactérias e interfere o processo de replicação e síntese dos ácidos nucleicos (RNA e DNA); mutações no gene $r p o B$ resultam em modificações conformais na subunidade $\beta$ da RNA polimerase, diminuindo a afinidade da rifampicina e concedendo resistência ao fármaco, desencadeando várias alterações nesse gene, sendo a troca de aminoácidos denominada $\mathrm{S} 456 \mathrm{~L}$, substituição de serina (TCG) por leucina (TTG) no códon 456, a mais comum (CAMBAU et al., 2018).

A dapsona tem como alvo a enzima diidropteroatosintase (DPHS), inibindo competitivamente seu substrato, o ácido paraminobenzoico, acarretando a interrupção da síntese de ácido fólico e purinas, evitando a formação de DNA e RNA. A resistência à dapsona se dá devido às mutações que ocorrem em códons no gene folP1, como por exemplo, a modificação $\mathrm{P} 55 \mathrm{~L}$, troca de prolina (CCC) por leucina (CTC) no códon 55 que fazem com que o fármaco não inicie a cascata de inibição (CAMBAU et al., 2018).

Em geral, a resistência às fluoroquinolonas ocorre através de mutações em regiões específicas nos genes estruturais, por exemplo, a mutação A91V, substituição da alanina (GCA) por valina (GTA) no códon 91 do gene, que faz com que o antibiótico não se ligue às enzimas. Esta é a mutação mais comum encontrada na presença desses fármacos. A DNA girase é o principal alvo das fluoroquinolonas no $M$. leprae e, esses medicamentos têm por mecanismo de ação inibir a replicação do DNA através de sua ligação com a subunidade A da DNA girase no gene gyrA. As trocas de aminoácidos nos códons do gene por meio de mutações, inibem a ligação das fluoroquinolonas com a subunidade A da DNA girase, conferindo resistência ao fármaco. (CAMBAU et al., 2018). 


\section{Metodologia}

Foi realizado um levantamento bibliográfico dos estudos sobre a resistência medicamentosa na hanseníase e seus aspectos, utilizando a pesquisa exploratória como metodologia de abordagem. Utilizaram-se guias e/ou manuais, teses e artigos em língua portuguesa, inglesa e espanhola das bases de dados: Medical Literature Analysis and Retrieval System Online (MEDLINE), Scientific Library Online (SciELO) e Google Acadêmico ${ }^{\circledR}$. Foram pesquisados os termos: resistência medicamentosa, hanseníase, poliquimioterapia em hanseníase e as combinações de palavras-chaves: "resistência medicamentosa" e "hanseníase", "recidiva" e "resistência medicamentosa", "recidiva" e "hanseníase", "alterações genéticas" e "hanseníase". Os métodos de exclusão de trabalhos foram filtro de data equivalente de 2009 a 2019 e trabalhos que, após a leitura completa dos mesmos, não se adequavam ao proposto pelo estudo (Figura 1).

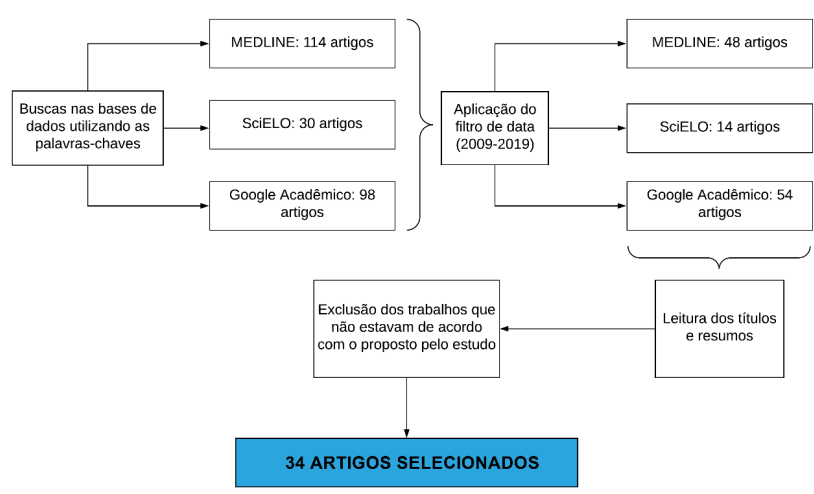

Figura 1: Fluxograma da metodologia de busca

As referências incluídas foram distribuídas conforme as chaves de interesse (Tabela 1), criadas a partir dos termos pesquisados.

Tabela 1: Distribuição das referências bibliográficas conforme chaves de interesse.

\begin{tabular}{l|c}
\hline Chaves de interesse & Total de artigos \\
\hline Resistência medicamentosa em hanseníase & 9 \\
Aspectos da resistência medicamentosa em hanseníase & 8 \\
Poliquimioterapia & 5 \\
Recidiva em hanseníase & 5 \\
Alterações genéticas na hanseníase & 7 \\
\hline
\end{tabular}

\section{Resultados e Discussão}

Os resultados dos artigos selecionados salientaram os aspectos e consequências da resistência medicamentosa na hanseníase em sua proporção histórica, clínica, epidemiológica e acerca das controvérsias na utilização dos medicamentos.

A maioria dos autores citou a dificuldade dos pacientes em tomar a medicação corretamente como um dos principais fatores que acarretaram consequências negativas na doença.

A figura 2 mostra a frequência da resistência encontradas aos fármacos de primeira e segunda linha para tratamento da hanseníase.

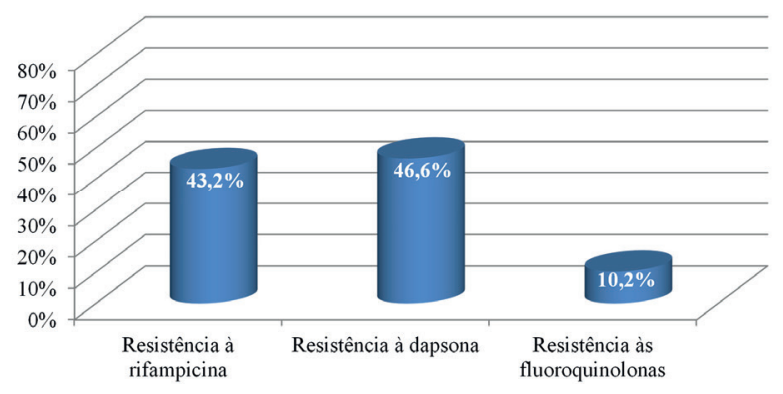

Figura 2: Frequência da resistência encontrada aos fármacos de primeira e segunda linha

As principais pessoas acometidas pela doença e pelos episódios de resistência (principalmente à rifampicina) e recidivas nos estudos foram do sexo masculino, moradores das regiões sudeste e nordeste do Brasil e de outros países, sul-americanos e asiáticos (Tabela 2).

Tabela 2: Epidemiologia da resistência à rifampicina detectada em regiões endêmicas para hanseníase em 2018.

\begin{tabular}{|c|c|c|c|}
\hline Região/País & $\begin{array}{l}\text { Menos de } 3 \text { casos de } \\
\text { resistência à } \\
\text { rifampicina }\end{array}$ & $\begin{array}{l}\text { De } 3 \text { até } 10 \text { casos de } \\
\text { resistência à } \\
\text { rifampicina }\end{array}$ & $\begin{array}{l}\text { Mais de } 10 \text { casos de } \\
\text { resistência à } \\
\text { rifampicina }\end{array}$ \\
\hline África & $\begin{array}{c}\text { Guiné, Mali, Burkina } \\
\text { Fasso, Benin, Níger, } \\
\text { Etiópia, Moçambique e } \\
\text { Madagascar }\end{array}$ & - & - \\
\hline Américas & - & Colômbia & Brasil \\
\hline Ásia & $\begin{array}{c}\text { Iêmen, Paquistão, China, } \\
\text { Vietnã e Filipinas }\end{array}$ & Myanmar e Indonésia & Índia \\
\hline Europa & - & - & - \\
\hline Oceania & - & - & - \\
\hline
\end{tabular}

Fonte: adaptado e traduzido de Cambau et. al (2018).

Os estudos citaram que a resistência medicamentosa foi uma das principais causas de recidivas em hanseníase, que podem ocorrer em período curto, logo após o tratamento ou depois de anos, conforme outros fatores extrínsecos (Tabela 3).

Tabela 3: Recidiva e resistência medicamentosa em casos de hanseníase

\begin{tabular}{c|c|c}
\hline \multicolumn{1}{c}{ Autor/Ano } & $\begin{array}{c}\text { Número de pacientes com } \\
\text { suspeita de recidiva }\end{array}$ & $\begin{array}{c}\text { Apresentou caso de resistência } \\
\text { medicamentosa }\end{array}$ \\
\hline DIÓRIO et al., 2009 & 28 & Sim \\
\hline DINIZ et al., 2009a & 142 & Sim \\
DINIZ et al., 2009b & 1 & Sim \\
\cline { 1 - 1 } BONA et al., 2015 & 56 & Não
\end{tabular}

A maioria das alterações genéticas foi encontrada no gene $r p o B$, que está ligado à resistência à rifampicina e, estão descritas na tabela 4 . Nesse gene, a principal alteração foi a troca de aminoácidos denominada $\mathrm{S} 456 \mathrm{~L}$, com a substituição de serina por leucina. No gene folP1, a principal modificação foi a $\mathrm{P} 55 \mathrm{~L}$, troca de prolina por leucina e, no gene responsável pela resistência às fluoroquinolonas $(g y r A)$, 
a mutação com principal destaque foi a A91V, substituição da alanina por valina.

Tabela 4: Principais mutações em genes ligados à resistência aos fármacos na hanseníase

\begin{tabular}{|c|c|c|c|c|}
\hline Autor/Ano & País de estudo & Fármacos & Gene & Alteração genética \\
\hline MATSUOKA, 2010 & $\begin{array}{c}\text { Japão, } \\
\text { Indonésia e } \\
\text { Coreia }\end{array}$ & $\begin{array}{c}\text { Rifampicina } \\
\text { Dapsona } \\
\text { Fluoroquinolona }\end{array}$ & $\begin{array}{l}r p o B \\
\text { folP1 } \\
\text { gyrA }\end{array}$ & $\begin{array}{l}\text { S425L, A410T, H420T } \\
\text { P55S, P55L, T53I } \\
\text { A91V }\end{array}$ \\
\hline $\begin{array}{l}\text { CAMBAU et al., } \\
2012\end{array}$ & França & $\begin{array}{c}\text { Rifampicina } \\
\text { Dapsona } \\
\text { Fluoroquinolona }\end{array}$ & $\begin{array}{l}r p o B \\
\text { folP1 } \\
\text { gyrA }\end{array}$ & $\begin{array}{l}\text { S456L, S456F, S456M, L458V, } \\
\text { H451Y, G432S, H451D, T433I, } \\
\text { D441Y, Q438V } \\
\text { T53A, T53I, T53V, P55R, P55L } \\
\text { A91V }\end{array}$ \\
\hline LIU et al., 2015 & China & $\begin{array}{c}\text { Rifampicina } \\
\text { Dapsona } \\
\text { Fluoroquinolona }\end{array}$ & $\begin{array}{l}r p o B \\
\text { folP1 } \\
\text { gyrA }\end{array}$ & $\begin{array}{l}\text { S425L } \\
\text { T53A } \\
\text { A91V }\end{array}$ \\
\hline $\begin{array}{l}\text { BELTRÁN-ALZATE } \\
\text { et al., } 2016\end{array}$ & Colômbia & $\begin{array}{c}\text { Rifampicina } \\
\text { Dapsona } \\
\text { Fluoroquinolona }\end{array}$ & $\begin{array}{l}\text { folPI } \\
\text { gyrA }\end{array}$ & $\begin{array}{c}\text { A441T, A505T, S458M, A426T, } \\
\text { S456L } \\
\text { T53A, T88P, P55L, A91H, } \\
\text { A94T } \\
\text { A107L }\end{array}$ \\
\hline ARAÚJO et al., 2017 & \begin{tabular}{|} 
Japão, Estados \\
Unidos, Brasil \\
e Bélgica
\end{tabular} & $\begin{array}{c}\text { Rifampicina } \\
\text { Dapsona } \\
\text { Fluoroquinolona }\end{array}$ & $\begin{array}{r}\text { folP1 } \\
\text { gyrA }\end{array}$ & $\begin{array}{c}\text { S456L, D441Y, H451Y, S456M, } \\
\text { T433I, G448D } \\
\text { T53I, P55L, P55R } \\
\text { A91V }\end{array}$ \\
\hline $\begin{array}{l}\text { WILLIAMS et al., } \\
2018\end{array}$ & Estados Unidos & $\begin{array}{l}\text { Rifampicina } \\
\text { Dapsona }\end{array}$ & $\begin{array}{l}r p o B \\
\text { folPI }\end{array}$ & $\begin{array}{c}\text { S456L } \\
\text { T53A, T53I, P55R, P55L }\end{array}$ \\
\hline ROSA et al., 2019 & Brasil & $\begin{array}{c}\text { Rifampicina } \\
\text { Dapsona } \\
\text { Fluoroquinolona }\end{array}$ & $\begin{array}{r}r p o B \\
\text { folP1 } \\
\text { gyrA }\end{array}$ & $\begin{array}{c}\text { S456M, S456L, L470G, A441T } \\
\text { P55A, P55L, T53A } \\
\text { L97P }\end{array}$ \\
\hline
\end{tabular}

Dezoito pacientes $(21,9 \%)$ se tratavam de casos de resistência primária, $19(23,2 \%)$ eram de registros de resistência secundária e os dados de 45 pacientes sobre esse domínio $(54,9 \%)$ não foram informados, como dispõe a tabela 5 .

Tabela 5: Quantidade e tipos de casos de resistência medicamentosa

\begin{tabular}{l|cccccc|cc}
\hline \multicolumn{1}{c|}{ Autor/Ano } & $\begin{array}{c}\text { Número de casos } \\
\text { de resistência } \\
\text { medicamentosa }\end{array}$ & RR & RD & RRDS & RF & RM & RP & RS \\
\hline MATSUOKA, 2010 & $\mathbf{9}$ & 1 & 3 & 3 & - & 2 & - & - \\
CAMBAU et al., 2012 & $\mathbf{2 2}$ & 13 & 8 & - & 1 & - & - & - \\
LIU et al., 2015 & $\mathbf{3}$ & - & - & 1 & - & 2 & 3 & - \\
$\begin{array}{l}\text { BELTRÁN-ALZATE et } \\
\text { al., 2016 }\end{array}$ & $\mathbf{1 0}$ & 4 & 4 & 1 & 1 & - & 4 & 6 \\
$\begin{array}{l}\text { ARAÚJO et al., 2017 } \\
\text { WILLIAMS et al., 2018 }\end{array}$ & $\mathbf{1 4}$ & - & 4 & 6 & 1 & 3 & - & - \\
ROSA et al., 2019 & $\mathbf{4}$ & - & 3 & 1 & - & - & 3 & 1 \\
\cline { 2 - 10 } & $\mathbf{2 0}$ & 2 & 4 & 12 & 2 & - & 8 & 12 \\
\hline
\end{tabular}

RR: resistência à rifampicina; RD: resistência à dapsona; RRDS: resistência à dapsona e rifampicina simultaneamente; RF: resistência às fluoroquinolonas; RM: resistência múltipla; RP: resistência primária; RS: resistência secundária.

Nenhum caso de resistência medicamentosa à clofazimina foi relatado.

O tratamento incorreto é um aspecto importante quando falamos de resistência medicamentosa na hanseníase, uma vez que ele tem papel marcante no aparecimento de casos (KAIMAL; THAPPA, 2009; FOGAGNOLO et al., 2009).
O fato dos principais países a apresentarem altas taxas de casos de resistência aos fármacos serem os sulamericanos (Brasil e Colômbia) e asiáticos (Índia, Myanmar e Indonésia), provavelmente se deva pela proporção da endemia da doença nessas áreas, logo, países com altas taxas de casos novos terão maiores taxas de casos de resistência medicamentosa (CAMBAU et al., 2018), além da transmissão dos bacilos resistentes nesses países (ROSA et al., 2019). Porém, também existe a presença de bacilos resistentes em países que, apesar de serem desenvolvidos, possuem áreas endêmicas de transmissão, sendo a maioria desses bacilos detectados em pessoas que migraram de áreas endêmicas onde a resistência aos fármacos estava presente (WILLIAMS et al., 2013; WILLIAMS et al., 2018).

As notificações de casos de recidiva associados à resistência medicamentosa são crescentemente mais comuns e resultam do melhor conhecimento das metodologias moleculares e dos principais genes envolvidos nessa ação (DIÓRIO et al., 2009). Estudos mostraram altos índices de pacientes com perfis de resistência medicamentosa que foram diagnosticados com recidiva em hanseníase (DIÓRIO et al., 2009; MATSUOKA, 2010; ROSA et al., 2019), o que reforça o papel da resistência aos fármacos no processo de reinfecção. Até os dias atuais, não existem estudos que abordem profundamente o fato da dapsona ser o principal fármaco que gera resistência no bacilo de Hansen, porém, esse dado talvez se explique pelo fato da dapsona ter sido usado como monoterapia para a hanseníase antes da implementação da terapia multidrogas. Outro dado entregue pelo estudo de Williams et al (2018) é que pelo fato de o tratamento principal ser uma associação de dapsona/rifampicina/clofazimina e que, as doses de dapsona e clofazimina são diárias enquanto que as doses de rifampicina são mensais, deixam o paciente com alta carga bacilar e com bacilos resistentes à dapsona, tomando apenas um medicamento eficaz (clofazimina) diariamente.

A presença de muitas mutações genéticas no gene rрo $B$ pode se explicar devido a sua grande quantidade de pares de bases (3.534 bp) e do gene ter regiões específicas que são propícias para mutações relacionadas à resistência medicamentosa no gênero Mycobacterium (CUEVASCÓRDOBA; ZENTENO-CUEVAS, 2010; MEJÍA, 2013).

Por se tratar de um esquema de associação de antibióticos, era esperado que ocorressem casos de pacientes com bacilos multirresistentes (resistentes a mais de um fármaco simultaneamente) (CAMBAU et al., 2018), porém, o que chamou a atenção nos artigos foi a quantidade de casos de resistência medicamentosa secundária, resistência que aparece durante um segundo tratamento. Esses tipos de casos se devem principalmente aos tratamentos incorretos e a persistência bacilar (ROSA et al., 2019).

Os casos de resistência medicamentosa à clofazimina são raros e pouco se sabe a seu respeito (MATSUOKA, 2010; MACHADO et al., 2018). As únicas pendências quanto ao uso da clofazimina na PQT são as reações adversas que ela pode causar nos pacientes (BRASIL, 2014).

A PQT é um esquema de tratamento considerado eficaz e, quando seguido corretamente, aumenta as chances de cura e diminui os episódios de resistência aos fármacos (BOECHAT; PINHEIRO, 2012). Uma de suas poucas desvantagens é o possível aparecimento de reações adversas 
e/ou intolerância aos medicamentos que a constituem, muitas das vezes por interações entre os próprios fármacos (BRUSCHI; LABRÊA; EIDT, 2011; MARQUES et al., 2012).

O estudo dos casos de resistência medicamentosa na hanseníase é essencial para o controle e busca da cura, porém o campo da pesquisa nessa área ainda é muito limitado; faltam estudos que busquem se aprofundar nos principais aspectos da resistência e seu aparecimento e programas e incentivos eficazes que possam melhorar os problemas no tratamento, para que assim possamos tirar a hanseníase do catálogo de doenças negligenciadas, uma vez que os impactos da doença na vida de seus portadores são irrefutáveis.

\section{Referências}

AKINOLA, R. O.; MAZANDU, G. K.; MULDER, N. J. A Quantitative approach to analyzing genome reductive evolution using protein-protein interaction networks: a case study of Mycobacterium leprae. Frontiers in Genetics, v. 7, n. 39, p. 1-12, 2016.

ALVES, E. D.; FERREIRA, T. L.; FERREIRA, I. N. Hanseníase: avanços e desafios. Brasília: Nesprom, 2014. $492 \mathrm{p}$.

ARAUJO, S. et al. QPCR-High resolution melt analysis for drug susceptibility testing of Mycobacterium leprae directly from clinical specimens of leprosy patients. Plos Neglected Tropical Diseases, v. 11, n. 6, p.1-18, 2017.

BELTRÁN-ALZATE, C. et al. Leprosy drug resistance surveillance in Colombia: the experience of a Sentinel Country. Plos Neglected Tropical Diseases, v. 10, n. 10, p. 1-12, 2016.

BOECHAT, N.; PINHEIRO, L. C. S. Leprosy and its Chemotherapy. Revista Virtual de Química, v. 4, n. 3, p. 247-256, 2012.

BONA, S. H. et al. Recidivas de hanseníase em Centros de Referência de Teresina, Piauí, 2001-2008. Epidemiologia e Serviços de Saúde, v. 24, n. 4, p. 731-738, 2015.

BRASIL. Portaria n⿳ 3125, de 7 de outubro de 2010. Aprova as diretrizes para vigilância, atenção e controle da Hanseníase. Brasília, 2010.

BRASIL. Maria Angela Bianconcini Trindade. Ministério da Saúde. Hanseníase na atenção básica: tratamento. Rio de Janeiro: Sistema de Universidade Aberta do SUS, 2014.

BRUSCHI, K. R.; LABRÊA, M. G. A.; EIDT, L. M. Avaliação do estado nutricional e do consumo alimentar de pacientes com hanseníase do ambulatório de dermatologia sanitária. Hansenologia Internationalis, v. 36, n. 2, p. 5361, 2011.

CAMBAU, E. et al. Detection of Antibiotic Resistance in Leprosy Using Geno Type Leprae DR, a Novel Ready-ToUse Molecular Test. Plos Neglected Tropical Diseases, v.
6, n. 7, p.e1739, 2012.

CAMBAU, E. et al. Antimicrobial resistance in leprosy: results of the first prospective open survey conducted by a WHO surveillance network for the period 2009-15. Clinical Microbiology and Infection, v. 24, n. 12, p. 1305-1310, 2018.

CHAVARRO-PORTILLO, B. et al. Mycobacterium leprae's evolution and environmental adaptation. Acta Tropica, v. 197 (105041), 2019.

CRESPO, M. J.; GONÇALVES, A. Avaliação das possibilidades de controle da hanseníase a partir da poliquimioterapia. Revista Portuguesa de Saúde Pública, v. 32, n. 1, p. $80-88,2014$

CUEVAS-CÓRDOBA, B; ZENTENO-CUEVAS, R. Tuberculosis drogorresistente: mecanismos moleculares y métodos diagnósticos. Enfermedades Infecciosas y microbiología clínica, v. 28, n. 9, p.621-628, 2010.

DINIZ, L. M. et al. Estudo retrospectivo de recidiva da hanseníase no Estado do Espírito Santo. Revista da Sociedade Brasileira de Medicina Tropical, v. 4, n. 42, p. 420-424, jul. 2009a.

DINIZ, L. M. et al. Recidiva de hanseníase em um paciente com resistência medicamentosa à rifampicina. In: SIMPÓSIO DE HANSENOLOGIA, 4., 2009, Cuiabá: Hansenologia Internationalis, p. 56-56, $2009 \mathrm{~b}$.

DIÓRIO, S. M. et al. Recidivas associadas à resistência a drogas na hanseníase. Hansenologia Internationalis, v. 34, n. 1, p. 37-42, 2009.

FOGAGNOLO, L. et al. Recidiva de hanseníase após 24 doses de poliquimioterapia multibacilar. Hansenologia Internationalis, v. 34, n. 1, p. 49-53, 2009.

KAIMAL, S.; THAPPA, D. Relapse in leprosy. Indian Journal of Dermatology, Venereology and Leprology, v. 75, n. 2, p. 126-135, 2009.

LAVANIA, M. et al. Molecular detection of multidrugresistant Mycobacterium leprae from Indian leprosy patients. Journal of Global Antimicrobial Resistance, v. 12, p. 214-219, 2018.

LIU, D. et al. Drug resistance in Mycobacterium leprae from patients with leprosy in China. Clinical and Experimental Dermatology, v. 40, n. 8, p. 908-911, 2015.

LUZHNOVA, S. A. et al. Experimental study of specific activity of 1.3-diazinon-4 com- pound PYaTd1 derivative in vivo. Zhurnal Mikrobiologii, Epidemiologii I Immunobiologii, v. 1, n. 5, p.18-22, 2016.

MACHADO, D. et al. Insights on Mycobacterium leprae Efflux Pumps and their implications in drug resistance and virulence. Frontiers in Microbiology, v. 9, 2018. 
MARQUES, G. F. et al. Esquema alternativo para tratamento de hanseníase multibacilar em um caso de hepatotoxicidade durante a poliquimioterapia.

Hansenologia Internationalis, v. 37, n. 2, p. 81-85, 2012.

MARRI, P. R.; BANNANTINE, J. P.; GOLDING, G.

B. Comparative genomics of metabolic pathways in Mycobacterium species: gene duplication, gene decay and lateral gene transfer. Fems Microbiology Reviews, v. 30, n. 6, p. 906-925, 2006.

MATSUOKA, M. Drug resistance in leprosy. Japanese Journal of Infectious Diseases, v. 63, n. 1, p. 1-7, 2010.

MEJÍA, M. C. C. Identificação de mutações em genes envolvidos na resistência medicamentosa de Mycobacterium leprae. 2013. 104 f. Dissertação (Mestrado em Imunologia Básica e Aplicada) - Universidade Federal do Amazonas, Manaus, 2013.

NOORDEEN, S. K. History of chemotherapy of leprosy. Clinics in Dermatology, v. 34, n. 1, p. 32-36, 2016.

OMS. Organização Mundial da Saúde. Estratégia global para Hanseníase 2016 - 2020. Nova Deli: OMS, 2016.

RATLEDGE, C.; DALE, J W. Mycobacteria: molecular biology and virulence: John Wiley \& Sons, 2009. 416 p.

ROSA, P. S. et al. Emergence and transmission of drug-/ multidrug-resistant Mycobacterium leprae in a Former Leprosy Colony in the Brazilian Amazon. Clinical Infectious Diseases, p. 1-8, 2019.

SMITH, C. S. et al. Multidrug therapy for leprosy: a game changer on the path to elimination. The Lancet Infectious Diseases, v. 17, n. 9, p.293-297, 2017.

WILLIAMS, D. L. et al. Drug resistance in patients with leprosy in the United States. Clinical Infectious Diseases, v. 58, n. 1, p.72-73, 2013.

WILLIAMS, D. L. et al. Dapsone resistance in Leprosy patients originally from American Samoa, United States, 2010-2012. Emerging Infectious Diseases, v. 24, n. 8, p. 1584-1585, 2018.

Recebido em: 09/03/2020

Aceito em: 10/11/2020 